\title{
What are Your Ideas? Canadian Journal of Neurological Sciences and 2003
}

Can. J. Neurol. Sci. 2003; 30: 1-2

This year will mark the final year of my first term with the Canadian Journal of Neurological Sciences (CJNS). The role has been a privilege and with the blessing of the Publications Committee of the Canadian Congress of Neurological Sciences, I hope to continue.

We have made some progress. Firstly, we continue to have a very dedicated and intelligent team behind CJNS that includes Sally Gregg, our Managing Director, Sue Impey, our Production Editor, and Myrna Gowing, the Adminstrative/Editorial Assistant. Without this team, CJNS would not exist. My collaboration with all remains enjoyable and very fruitful, day in and day out. A major effort accomplished was the substantial shortening of review times for submitted papers. While regular issues of CJNS continue to be published quarterly, we believe that authors benefit from more rapid decision making allowing a paper to be classified as "in press" rather than "submitted". As CJNS grows (and submissions are up substantially) we hope to publish more frequently, but not at the expense of manuscript quality. Our impact factor is slowly rising and currently exceeds that of most Canadian subspecialty journals. It can rise quite a bit further with your input. Considerations by those submitting work need not be limited by the current name of the journal. Some very highly ranked journals include geographical information in their name, including locations south and east of Canada. The message to authors is to send us your best work; CJNS has published, and continues to publish, high quality work from around the world and we welcome international submissions.

Some of our supplements will appear between regular issues of CJNS. Over the past year, we have worked with supplement editor Werner Becker to publish an important migraine supplement to CJNS and we are publishing, under the leadership of Oksana Suchowersky, a comprehensive movement disorder supplement this year. This piece represents knowledge imparted by the movement disorders group during their annual courses for residents. It will be an extremely useful learning supplement for all readers of CJNS, particularly neurologists like myself who are not subspecialists in the area of movement disorders. An important point to emphasize is that all of our supplements continue to be peer-reviewed, a laborious process that nonetheless distinguishes CJNS from other supplement publishers.

Our external referees have shifted to our accelerated demands on their time with impressive dedication. They are the second main reason CJNS exists and I thank them for their service. In this issue, we list our external referees who helped in 2002.

We have more work to do to launch CJNS into the higher impact ranks of neurological and neuroscience journals where it belongs. In 2003, we will begin to publish our Canadian Association of Neurosciences review articles. We will make a major effort to capture more neuropathological conferences and we continue to encourage all residency programs to send them to us. In 2003, we will publish further exchange work with the Neurological Journal of Southeast Asia. We would like to include more neuroimaging highlights from centres around the world. Guidelines for authors considering submitting neuropathological conferences or neuroimaging highlights are now posted on the CJNS website.

Finally, and probably most importantly, we are now fully electronic and have an enthusiastic team under the leadership of Dr. Daniel Keene facilitating your continuing medical education through the new CJNS and CCNS websites.

Send us your best work and your ideas.

Douglas W. Zochodne Editor-in-Chief 


\section{Thank you to our Reviewers}

We are indebted to the expert referees who have reviewed submission to the Canadian Journal of Neurological Sciences in 2002 (names in bold reviewed five or more papers). Their thoughtfulness and expertise has served our journal well.

Harold Adams
Coleen Adams
Eric Ahlskog
Duncan Anderson
Lee Ang
Henry Barnett
Werner Becker
Robert Bell
Brien Benoit
Timothy Benstead*
Mark Bernstein
Jose Biller
Shawn Bird
Sandra Black
Julien Bogousslavsky
Charles Bolton
Vera Bril
William Brown
Robert Brownstone
Donald Brunet
Joseph Bruni
Valentine Brussee
Alastair Buchan
Gregory Cairncross*
Donald Calne
Peter Camfield
Richard Camicioli
Robin Casey
Colin Chalk
Linda Chang
Robert Chen
Howard Chertkow
Sylvain Chouinard
Fred Colbourne
Paul Cooper
Dale Corbett
Bernard Corenblum
Alain Dagher
Andrew Demchuk
Richard Desbiens*
Dennis Dickson
Christopher Doig
Andre Douen
Christopher Dowd
Pierre Duquette
John Eds

\begin{tabular}{|c|c|}
\hline Thomas Feasby & Anthony Lang \\
\hline Michael Fehlings & Robert G. Lee \\
\hline Howard Feldman & Stan Leung \\
\hline J. Max Findlay* & William J. Logan \\
\hline William Fletcher* & Andres Lozano* \\
\hline Peter Forsyth & Ami Mankodi \\
\hline Mark Freedman & Wayne Martin \\
\hline Marvin Fritzler & Warren P. Mason \\
\hline Sarah Furtado & Edith McGeer \\
\hline Serge Gauthier & Jeannette McGlone \\
\hline Marek J. Gawel & David McNeely \\
\hline Francois Grand'Maison & Michel Melanson \\
\hline Robert Griggs & Ivar Mendez \\
\hline Alan Guberman & Luanne M. Metz \\
\hline Mark Guttman & Gyl Midroni \\
\hline Anthony Hakim & Gerard Mohr \\
\hline Mark Hallett & William Morrish \\
\hline Mohamed Hassan & Dwight Moulin \\
\hline Michael Hill & Richard Moulton \\
\hline David Hogan & S. Terence Myles* \\
\hline Renn Holness* & Sukriti Nag \\
\hline Christopher Honey & Avi Nath \\
\hline Robin Hsiung & Michael W. Nicolle \\
\hline William $\mathrm{Hu}^{*}$ & John Norris \\
\hline Mark Hudon* & John Noseworthy* \\
\hline R. John Hurlbert & Brian O’Neill \\
\hline Alan Jackson* & Andrew Parrent \\
\hline Joe Jankovic & David Patry \\
\hline Jack Jhamandas* & Christopher Patterson \\
\hline Mandar Jog & David Pelz \\
\hline Michael Jones & James Perry \\
\hline Fabrice Joulia & Kenneth C. Petruk \\
\hline Anthony Kaufmann & Stephen Phillips \\
\hline Andrew Kertesz & Neelan Pillay \\
\hline Joep Killestein & Christopher Power \\
\hline Michael King & William Pryse-Phillips \\
\hline Andrew Kirk & Allan Purdy \\
\hline Zelma Kiss & Alexander Rajput \\
\hline Jeffrey Kleim & David Ramsay* \\
\hline David Knopman & Peter M. Richardson* \\
\hline Bryan Kolb & Jean Rivest \\
\hline Douglas Kondziolka* & James Rutka \\
\hline Jeffrey Kordower & Dessa Sadovnick \\
\hline Robert Korneluk & Paul Sandor \\
\hline Anne-Louise LaFontaine & Philip Scheltens \\
\hline Terrence Lagerlund & Giovanni Schifitto \\
\hline
\end{tabular}

Jan Schwab

Shashi Seshia*

Kapil Sethi

Michael Shevell*

Ashfaq Shuaib

John Sladky

Benn Smith

Sian Spacey

J. David Spence

Richard Stein

Paul Steinbok*

John D. Stewart

A. Jon Stoess1*

Michael Strong

Oksana Suchowersky

Garnette Sutherland

Mark Tarnopolsky

Charles Tator

Philip Teal

Jeanne Teitelbaum

J. Toole

Joseph Tsui

Jean-Guy Villemure

Harry Vinters

Christopher Wallace

Cheryl Waters

Donald Weaver

Norman Weinberger

Brian Weinshenker

Richard Wennberg

Michael West

Brian Wheelock

Chris White*

Samuel Wiebe*

Eelco Wijdicks

Robert Willinsky

Peter Wong

John Wong

W. Barrie Woodhurst

Jerome Yager

Frank Yatsu

W. Yong

G. Bryan Young

Zonghang Zhao 